\title{
The Relative Value of Measures of Omega-3 Index, Perceived Stress, Cortisol and Sleep Time in Identifying Depression Among a Cohort of Australian Adolescents
}

\author{
Ross Grant ${ }^{1,3,6,{ }^{*}}$, Ayse Bilgin ${ }^{2}$, Jade Guest ${ }^{1,3}$, Margaret J. Morris ${ }^{3}$, Manohar Garg ${ }^{4}$ and \\ Robyn Pearce ${ }^{5}$
}

${ }^{1}$ Australasian Research Institute, Sydney Adventist Hospital, Sydney, Australia

${ }^{2}$ Department of Statistics, Faculty of Science, Macquarie University, Sydney, Australia

${ }^{3}$ Department of Pharmacology, School of Medical Sciences, UNSW, Callaghan NSW, Australia

${ }^{4}$ School of Biomedical Sciences and Pharmacy, University of Newcastle, Callaghan NSW, Australia

${ }^{5}$ Lifestyle Research Centre, Avondale College of Higher Education, Cooranbong NSW, Australia

${ }^{6}$ Sydney Adventist Hospital Clinical School, University of Sydney, Sydney, Australia

\begin{abstract}
Objective: To assess the relative prognostic value of 11 variables including, omega-3, perceived stress, cortisol and sleep duration, in predicting adolescent depression.

Design, Setting and Participants: A cross-sectional study of 444 healthy adolescents aged 16-18 years, from 10 schools within the Northern Sydney and Central Coast regions of New South Wales, Australia. Participants provided blood and saliva samples and completed questionnaires. Statistical classification methods were used to model the relationships between the predictors and depression.

Main Outcome Measures: relative predictive value of each variable in correctly classifying depression.

Results: $6 \%$ of boys and $9 \%$ of girls were categorised as experiencing severe to extremely severe depression. $4 \%$ of boys and $10 \%$ of girls were categorised as experiencing severe to extremely severe stress. The mean AM:PM cortisol for boys, $22 \pm 101$, was higher than that of girls, $11 \pm 10$. The average omega-3 index for boys, 10.5 \pm 3.7 , was also higher than that of girls, $7.7 \pm 2.6$. The average sleep duration of $7.8 \pm 1.1 \mathrm{hrs}$ showed no gender differences.

The best classification model identified perceived stress as the most significant predictor of depression followed by BMI and omega-3 index. Cortisol ratio was a significant discriminator for boys but not girls. When stress was excluded, shorter sleep duration became a significant discriminator in both boys and girls with waist to hip ratio providing further discrimination in girls only.

Conclusion: The strongest predictor of depression in adolescents was perceived stress followed by higher BMI and lower omega-3 levels. These findings provide a rational basis for establishing program priorities for the prevention and treatment of adolescent depression.
\end{abstract}

Keywords: Child, depression, adolescent, omega-3, sleep, BMI, cortisol.

\section{INTRODUCTION}

Depression is an emotional state characterised by helplessness and powerlessness. Importantly, the prevalence of depression increases, and its incidence peaks, during adolescent development [1, 2]. This burden of depression negatively impacts many important facets of a young person's life including, educational achievement, social engagement and overall health $[1,3]$. Depression is also a leading predictor of suicidal ideation and behaviour [4]. With half of all lifetime mental disorders such as depression initiated by mid-teens and three quarters by the early 20s [5], preventing the early experience of depression

*Address correspondence to this author at the Sydney Medical School \&Australasian Research Institute, Sydney Adventist Hospital, 185 Fox Valley Rd Wahroonga, NSW, Sydney, Australia; Tel: +61 (2) 94879602;

Fax: +61 (2) 94879626; E-mail: rossg@sah.org.au impacts not only a young person's present mental and physical state but also their future quality of life.

The development of depression has a multifactorial etiology encompassing a person's heritable biology and its response to social, physical and nutritional pressures. Negative early experiences, perceived lack of social support and stressful life events (e.g. trauma and loss) are well established psychosocial contributors [6]. Poor weight management, often as a consequence of emotional eating and attendant social stress, may also play a part [7]. However the subjective experience of depression necessarily develops as a consequence of specific changes in the neurobiology of the brain. An individual's vulnerability to depression, relative to a given set of stressors, may therefore vary depending on both their inherited and cultivated neurobiology. 
Though many candidate genes have been investigated over a number of years there is yet no consistent evidence to support the role of any specific gene in the development of major depressive disorder [8]. This suggests that the environment interacts with an individual's genotype in many different ways to achieve the brains remodelling into its 'depressed' phenotype. While psychosocial stressors have been clearly identified as promoters of depression, certain modifiable lifestyle choices may also remodel the brain biology in ways that promote the experience of depression. Choices that are relevant to the modern adolescent lifestyle include nutritional quality (in particular omega-3 intake) and time for rest (i.e. sleep).

Using self-reported responses to questions relating to emotional state (stress, anxiety) and sleep quantity and quantitative measurements of omega- 3 index and cortisol (AM:PM) this study sought to determine the relative predictive value of these measures in correctly classifying the depression status of a cohort of 16-18 year old adolescents in a metropolitan Australia setting.

\section{METHODS}

A cross-sectional survey of 444 participants (266 female, 178 male) aged 16 to 18 years was carried out.

\section{Morphometric Analysis}

The height and weight of each participant was measured using a standard Wedderburn height stick $(\mathrm{mm})$ and Wedderburn body composition analyser BC420MA. BMI was calculated appropriate to age using the 2000 CDC growth charts developed by the National Centre for Health Statistics in collaboration with the National Centre for Chronic Disease Prevention and Health Promotion [9]. The waist to hip ratio was determined by dividing the waist circumference (measured midway between the top of the ileac crest and the lowest rib) by the hip circumference (the distance around the widest point of the buttock).

\section{Survey Information}

Participants provided written responses to questions detailing their personal demographics and use of omega-3 supplements. The prevalence of depression, anxiety and stress in this adolescent cohort was assessed using self-reported responses to the Depression, Anxiety, Stress scales (DASS) questionnaire [10].

\section{Recruitment and Exclusion Criterion}

Participants were recruited from students in year 11 from 10 schools within the Northern Sydney and Central Coast metropolitan areas as part of a larger health study. No apparently healthy student was actively prevented from participating. All participants provided written informed consent signed by both themselves and their legal guardian.

\section{Blood Sample Collection}

A whole blood sample ( $200 \mu \mathrm{L})$ was collected from each participant between 0830 and 1000 hours via finger-prick in two heparin anticoagulated capillary tubes and stored at $4-80^{\circ} \mathrm{C}$ for $<4 \mathrm{hrs}$ before processing.

\section{Fatty Acid (Omega-3) Analysis}

A comprehensive range of fatty acids were analysed by gas chromatography (GC) based on the methods of Lepage and Roy [11], as previously reported [12].

\section{Omega-3 Index}

Omega-3 Index is a validated reliable measure of long-term omega-3 PUFA intake and has been documented to reflect tissue levels of EPA/DHA $[13,14]$.

For the purpose of this study the whole blood omega-3 index is defined as the percentage of the long chain polyunsaturated fatty acids, ecosopen-tanoic acid $(E P A)+$ docosohexanoic acid (DHA) relative to total fatty acid content in the whole blood. To facilitate comparison with published data on the erythrocyte omega-3 Index, the whole blood omega-3 status as determined in this study was converted to the equivalent omega-3 index using an average of the conversion factors calculated by using published data by Bell et al. [15], for EPA (average of 1.3582 and $1.3186)=1.3384$ and $\mathrm{DHA}(2.2121$ and 2.2202$)=$ 2.2242 .

\section{Cortisol (Saliva) Collection}

Participants were requested to collect two cortisol (saliva) samples: 1) An evening (resting) sample at the time the adolescent normally goes to bed. 2) A morning (waking) sample when the adolescent initially wakes, but while still in bed.

To collect these samples participants were instructed to. 1) Place the cotton swab provided into 
the mouth and chew gently, allowing it to soak with saliva for 3 minutes. 2) Place the 'chewed' swab into the pre-labelled test tube provided. The next day participants brought the receptacles to school where they were collected by a member of the research team and stored at $-80^{\circ} \mathrm{C}$ until analysis.

\section{Cortisol Analysis}

Saliva cortisol levels were tested using the electrochemiluminescence immunoassay "ECLIA" method developed by Roche diagnostics (USA) (cat\#: cortisol-1175116 1122v19.0) and analysed on a Cobas6000 e601 immuno analyser.

\section{Statistical Analysis}

Five classification methods were used to identify the relative predictive value of each of the variables including stress, omega-3 polyunsaturated fatty acid (PUFA) intake and sleep, on depression. These methods included the Classification and Regression Tree (C\&RT), Support Vector Machines (SVM), Neural Network (NN), CHAID, and C5.0 Tree [16, 17]. A classification model was considered successful when it consistently returned high predictive accuracy rates across all three categories of depression (i.e. no depression, mild depression, extreme depression). This technique is considered more accurate than randomly allocating individuals into depression categories. All models were developed using IBM SPSS Modeller 14.
Two sets of models were developed using the predictor variables. In the first set, anxiety and stress scores were included with other predictors. The anxiety and stress score variables were then removed to identify the impact of physiological and nutritional variables on being able to classify individuals into each depression category. For each of the five classification models, class specific accuracy rates as well as overall model accuracy was calculated to identify the best model. In addition, model predictions were compared to random predictions (class specific lifts) to decide which model was best for future prediction. Responses from 10 participants to the DASS were incomplete and therefore their depression category could not be specified. These were excluded from the analysis.

\section{Identifying the Best Classification Model}

For each of the five classification models, depression (divided into three categories: no depression ( $n=307)$, mild depression $(n=92)$, extreme depression $(n=35))$, was specified as the outcome variable. Predictor variables (listed in Table 1) were then used to identify potential underlying associations with each of the three depression categories.

After modelling the data using each of the five classification methods the C5.0 decision tree was identified as the best model for its ability to accurately predict the depression category for each participant. Its

Table 1.

\begin{tabular}{|c|c|c|c|c|c|c|}
\hline Predictor Variables & Coding/Calculation (n) & Observations (n) & Minimum & Maximum & Mean & SD \\
\hline Night cortisol $^{\mathrm{C}}$ & & 417 & .5 & 435.7 & 5.6 & 25.0 \\
\hline Morning cortisol $^{\mathrm{C}}$ & & 417 & 1.1 & 911.1 & 27.4 & 68.3 \\
\hline Cortisol difference $^{c}$ & Difference between morning and night & 392 & -6.2 & 858.3 & 24.2 & 67.9 \\
\hline Omega-3 index ${ }^{c}$ & & 251 & 2.1 & 22.3 & 8.3 & 3.2 \\
\hline Sleep $(\mathrm{hrs})^{\mathrm{C}}$ & & 443 & 2.8 & 10.0 & 7.6 & 1.1 \\
\hline $\mathrm{BMI}^{\mathrm{C}}$ & & 444 & 13.1 & 38.5 & 22.3 & 3.6 \\
\hline Waist hip ratio ${ }^{c}$ & & 443 & 0.47 & 1.3 & 0.8 & 0.1 \\
\hline Cortisol AM:PM ratio ${ }^{c}$ & & 412 & 0.04 & 126.7 & 11.6 & 11.6 \\
\hline Gender $^{b}$ & $\begin{array}{c}\text { Female (266) } \\
\text { Male (178) }\end{array}$ & 444 & $\mathrm{n} / \mathrm{a}$ & $\mathrm{n} / \mathrm{a}$ & $n / a$ & $\mathrm{n} / \mathrm{a}$ \\
\hline Anxiety $^{\circ}$ & $\begin{array}{c}\text { None (284) } \\
\text { Mild (97) } \\
\text { Extreme (52) Missing (11) }\end{array}$ & 406 & $n / a$ & $\mathrm{n} / \mathrm{a}$ & $n / a$ & $n / a$ \\
\hline Stress $^{\circ}$ & $\begin{array}{c}\text { None (316) } \\
\text { Mild (86) } \\
\text { Extreme (31) Missing (11) }\end{array}$ & 406 & $n / a$ & $n / a$ & $\mathrm{n} / \mathrm{a}$ & $\mathrm{n} / \mathrm{a}$ \\
\hline
\end{tabular}

Predictor Variables for the Classification Models.

Data type: ${ }^{b}$ binary, ${ }^{\circ}$ continuous, ${ }^{\circ}$ ordinal. 
algorithm identifies the variables with the highest information gain for the best split point so that a large collection of records can be divided into successively smaller sets of records. A C5.0 decision tree was grown for this dataset by setting the pruning severity to $75 \%$ and minimum records for each leaf to 5 . Ten-fold cross-validation was tried and found not to make any difference to the accuracy of the predictions.

\section{Ethical Approval}

This study was conducted in accordance with the Helsinki declaration. Approval was obtained from the Human research Ethics Committee (HREC) of the Sydney Adventist Hospital (HREC\# 06/08).

\section{RESULTS}

\section{Prevalence of Depression}

Overall $78.3 \%$ of boys and $65.6 \%$ of girls indicated no signs of depression, $7.4 \%$ of boys and $12.4 \%$ of girls indicated signs of mild depression, $8 \%$ of boys and $12.7 \%$ of girls responses were consistent with moderate depression, $4 \%$ of boys and $3.9 \%$ of girls responses were consistent with severe depression and $2.3 \%$ of boys and $5.4 \%$ of girls responses were consistent with extremely severe depression. As numbers were low in the higher depression classifications, to improve statistical power, these five groups were collapsed into three categories, no depression, mild to moderate depression and severe to extremely severe depression. The prevalence of depression based on these categories is presented in Figure 1.

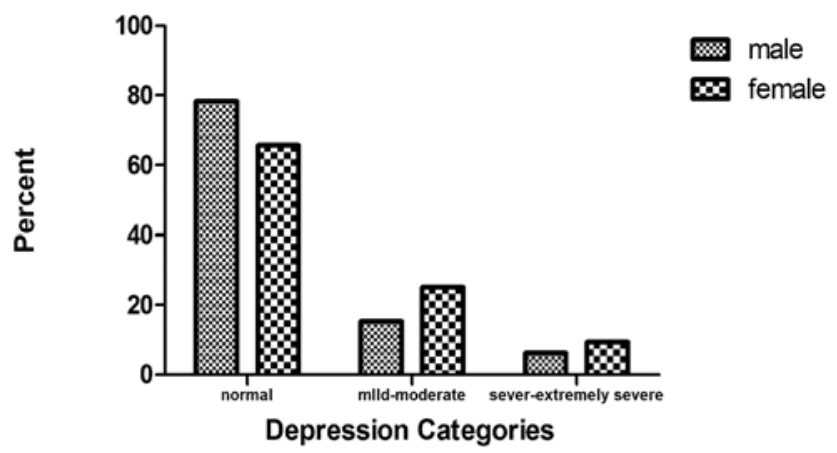

Figure 1: Percentage distribution of adolescents across three depression categories based on written answers to the DASS questionnaire.

\section{Prevalence of Stress}

Overall $84.5 \%$ of boys and $65.6 \%$ of girls indicated feeling no stress, $9.2 \%$ of boys and $11.6 \%$ of girls indicated having mild stress, $2.9 \%$ of boys and $13.1 \%$ of girls moderate stress, $2.9 \%$ of boys and $7.7 \%$ of girls as having severe stress and $0.6 \%$ of boys and $1.9 \%$ of girls as experiencing extremely severe stress. Similar to the depression classifications, numbers were also low in the higher stress classifications. To improve statistical power, these five groups were again collapsed into the three categories, no stress, mild to moderate stress and severe to extremely severe stress. The prevalence of stress in this adolescent population, based on these categories is presented in Figure 2.

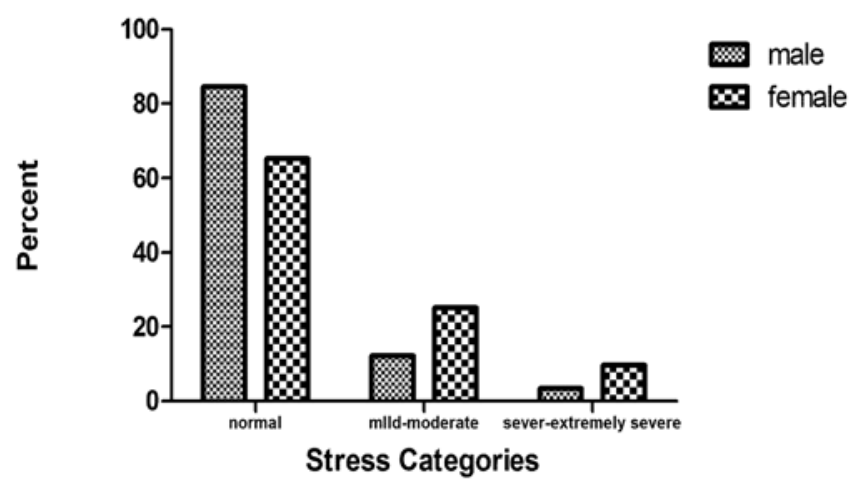

Figure 2: Percentage distribution of adolescents across three stress categories based on written answers to the DASS questionnaire.

\section{Cortisol AM:PM ratio}

$\mathrm{AM}$ and PM plasma cortisol ratios were determined as an indicator of pituitary-adrenal function where higher AM and low PM cortisol is indicative of a lower stressed state. On average the AM:PM ratio for boys was $22( \pm 100)$ and for girls $11( \pm 10)$ (Figure 3). These were not statistically different (Table 2 ).

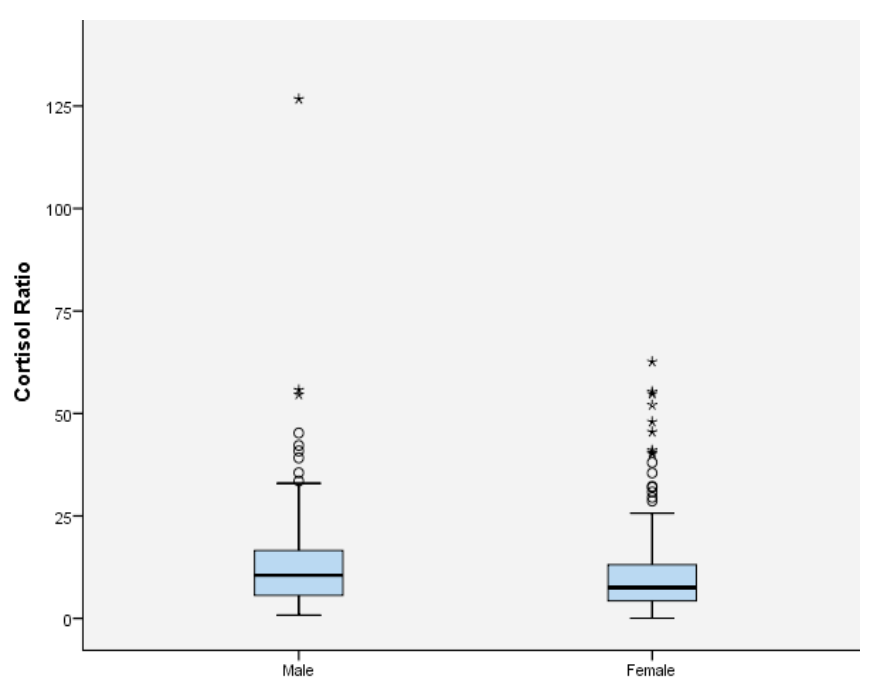

Figure 3: Distribution of $\mathrm{AM}: \mathrm{PM}$ cortisol ratios for male and female adolescents. 
Table 2:

\begin{tabular}{|c|c|c|c|c|c|c|}
\hline Biomarker & Gender & $\mathbf{n}$ & Minimum & Maximum & Mean & SD \\
\hline \multirow[t]{2}{*}{ BMI } & Female & 266 & 13.1 & 35.6 & 22.2 & 3.8 \\
\hline & Male & 178 & 15.5 & 38.5 & 22.4 & 3.3 \\
\hline \multirow[t]{2}{*}{ Waist hip ratio } & Female & 266 & 0.5 & 1.1 & 0.8 & 0.1 \\
\hline & Male & 177 & 0.6 & 1.3 & 0.8 & 0.1 \\
\hline \multirow[t]{2}{*}{ Omega-3 index } & Female & 192 & 2.1 & 18.8 & 7.7 & 2.6 \\
\hline & Male & 59 & 4.3 & 22.3 & 10.5 & 3.7 \\
\hline \multirow[t]{2}{*}{ Sleep (hrs) } & Female & 266 & 2.9 & 9.8 & 7.5 & 1.1 \\
\hline & Male & 177 & 2.75 & 10.0 & 7.7 & 1.0 \\
\hline \multirow[t]{2}{*}{ Cortisol ratio } & Female & 258 & 0.0 & 62.6 & 10.5 & 10.1 \\
\hline & Male & 155 & 0.8 & 1258.1 & 21.5 & 100.9 \\
\hline
\end{tabular}

Adolescent characteristics.

\section{Using the C5.0 Classification Model to Identify the Best Predictor Variables of Depression}

When anxiety and stress were included among the possible predictive variables the C5.0 classification model identified stress as the most important variable in categorizing a person into the different depression categories (i.e. no depression, mild depression, extreme depression). The self-reported anxiety measure was not found to be statistically predictive in any model and was therefore excluded from further analyses. Cortisol ratio, omega-3 index, BMI, gender and waist hip ratio were also statistically significant predictors for assigning participants to the correct depression categories. Other predictor variables did not help for classification and were therefore excluded from the final decision tree.

The overall accuracy of this model is $78.8 \%$. This model was able to classify $94.14 \%$ of non-depressed participants correctly into the non-depressed category, $45.65 \%$ of the mildly depressed participants and $54.29 \%$ of the extremely depressed participants into their correct categories. The model is 6.7 times better than randomly choosing extremely depressed participants and 3.12 times better for mildly depressed participants.

All the participants classified as having no stress were classified correctly by the C5.0 model into the no depression category (Figure 4). Although included into the models, anxiety was not identified as one of the important variables for predicting participants' depression category. Overall this model correctly classified participants into the three categories $85.9 \%$ of the time.
If the participants were in the mildly stressed category then variables other than stress proved useful for correct classification. If the BMI of participants was greater than 22.8 then omega-3 index contributed to the classification. If omega- 3 index was $>5.9 \%$ then participants were more likely to be classified as mildly depressed. This classification was correct for $51.4 \%$ of these participants. If omega-3 index was $\leq 5.9 \%$ then participants were more likely to be classified as extremely depressed (Figure 4). This classification was correct for $69.2 \%$ of these participants.

If the BMI of participants was $\leq 22.8$ participants were split by gender. If they were male then the cortisol ratio was effective in predicting no depression (cortisol ratio $\geq 10.22$ ) and mild depression (cortisol ratio $\leq 10.22$ ). These classifications were accurate in predicting the correct depression category for $83.3 \%$ and $76.2 \%$ of these participants respectively.

For the remaining female participants a clear and meaningful differentiation between the remaining nondepressed and mildly depressed females was not possible with the available variables.

\section{Excluding Stress as Predictor}

As the stress variable was a very strong predictor of depression, the data were reanalysed after excluding the predictor variables stress and anxiety, using the five statistical models. This allowed identification of possible contributions by other variables, in particular gender differences, to be revealed (Figure 5).

Although overall accuracy of the model decreased from $78.8 \%$ to $72.5 \%$ after excluding stress as a 


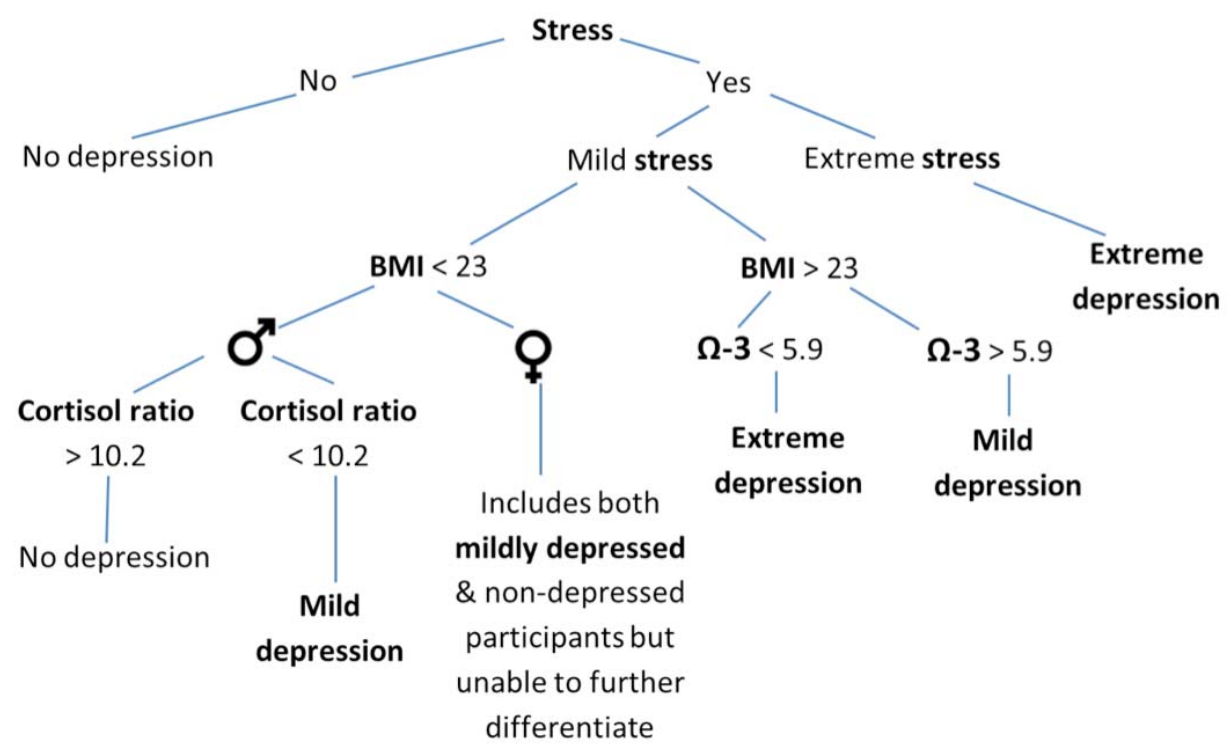

Figure 4: Decision tree hierarchy representing the relative discriminating power of the key variables; stress, BMI, omega-3 and cortisol ratio to the correct classification of adolescents into the specified depression categories.

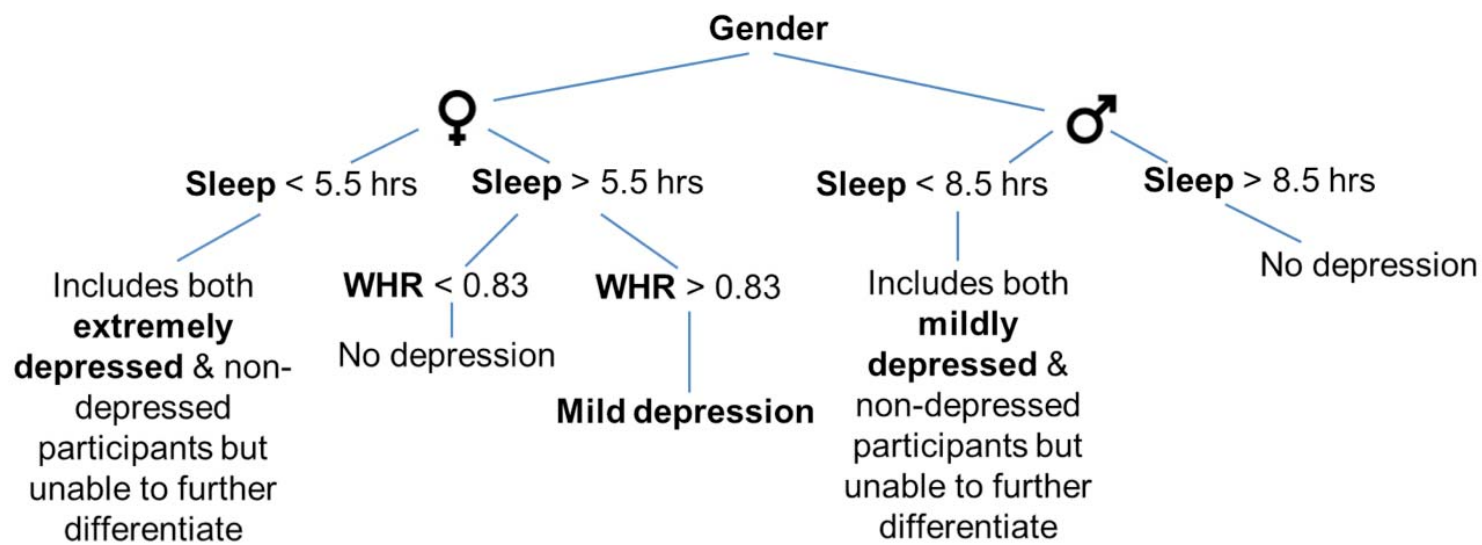

Figure 5: Decision tree hierarchy after excluding stress from the model, representing the relative discriminating power of additional variables such as gender, sleep and waisthip ratio in further classifying adolescents into the specified depression categories.

predictor, the C5.0 model still proved to be the best classification model. Under these conditions, gender, sleep duration and waist hip ratio were identified as important contributing variables in accurately predicting a child's depression category. This model was able to classify $97.4 \%$ of non-depressed participants correctly into the non-depressed category, $20.7 \%$ of the mildly depressed participants and $11.4 \%$ of the extremely depressed participants into their correct categories. The model is 8.46 times better than randomly choosing extremely depressed participants and 2.9 times better for mildly depressed participants.

If the participants were male then sleep duration was the most important variable in predicting depression. If male participants slept $>8$.5hours per day then they were classified as having no depression.
This classification was correct for $85.8 \%$ of the participants. For those male participants who slept $\leq 8.5$ hours per day a clear and meaningful differentiation between the remaining non-depressed and mildly depressed males was not possible with the available variables. None of the male participants were classified as extremely depressed by this model.

If the participants were female then in addition to number of hours of sleep, waist to hip ratio was also useful in classification. For those female participants who slept $\leq 5.5$ hours per day a clear and meaningful differentiation between the remaining non-depressed and extremely depressed females was not possible with the available variables. If female participants slept $>5.5$ hours per day and their waist hip ratio was $\leq 0.83$ then they were classified as having no depression 
(accuracy $70.5 \%$ ). However if their waist to hip ratio was $>0.83$ then they were classified as mildly depressed (accuracy 58.8\%).

\section{DISCUSSION}

The link between psychosocial stress, chronic activation of the hypothalamic-pituitary-adrenal (HPA) axis and depression is well established [18, 19]. Previous investigators have also recognized associations between modifiable lifestyle variables such as omega-3 PUFA intake and sleep duration and the development of depression [20, 21]. However to our knowledge this is the first study to investigate the relative power of each of these variables to predict depression in an adolescent cohort.

In this study, $15 \%$ of boys and $25 \%$ of girls were classified as experiencing mild to moderate depressive symptoms while $6 \%$ of boys and $9 \%$ of girls were classified as experiencing severe to extremely severe depressive symptoms (Figure 1). This is consistent with the greater incidence of depression in girls compared to boys as well as accepted prevalence data of $3-8 \%$ for major depression in adolescent populations from representative western societies such as Australia and the USA [22-24].

Using the C5.0 classification model the best predictor variable of depression was found to be the child's perceived feelings of stress where all children who reported no-stress also reported no symptoms of depression. This was not unexpected, psychosocial stressors such as unfavourable childhood events, perceived lack of social support, and recent stressful events have been well documented as significant risk factors for the development of a depressed phenotype $[25,26]$.

While perceived stress was clearly the dominant predictor of depression we further investigated how other important variables such as omega-3 index, cortisol ratio and sleep compared in their relative power to predict depression. As a secondary predictive variable, adolescent omega-3 PUFA levels did provide significant discriminatory power, above both cortisol ratio and sleep duration. For those participants with BMls above 23, having a lower omega-3 index of $<5.9 \%$ (ideal $>8 \%$ ) increased the risk of depression. Epidemiological studies as well as clinical trials have consistently indicated an important role for omega-3 PUFA in the pathogenesis of depression in both adults and adolescents [27-30]. While the mechanism(s) behind this association is/are still not completely understood it is significant that the omega-3 PUFA DHA is the most abundant fatty acid in the human brain. During adolescence the brain goes through a critical stage of neural development [31], where selective synaptic elimination and neural network remodelling occur, the success of which may be influenced by both environmental and neurobiological (e.g. omega-3 PUFA) factors. DHA has been shown to progressively increase in concentration in the brain from childhood through adolescence, peaking at around 18 years to adult levels [32]. While the functional importance of this is still being elucidated, dietary DHA intake has been associated with alterations in activity in cortical attention networks in healthy boys [33]. Reduced levels of omega-3 PUFA during adolescence may therefore predispose some children to a more disordered processing in key brain regions [34], increasing the risk of depression. Consistent with this it was noted in this study that no child with an omega-3 index above $5.9 \%$ reported severe to extremely severe depression. Therefore maintaining higher omega-3 PUFA levels may help blunt the impact of negative psychosocial stressors in children and thereby reduce development of the neurobiological changes associated with the more severe depressed phenotype.

Salivary AM:PM cortisol ratio is a measure of pituitary-adrenal activation, where a higher AM and low PM cortisol is indicative of a lower stressed state. In this study, reduced AM:PM cortisol ratios in boys with BMls $<23$ was an effective predictor of mild depression (Figure 4). The link between HPA activation and depression is well documented in adults with some recent evidence also in adolescents [35, 36]. However, cortisol ratios were an effective discriminator for boys but not for the girls in this study. The reasons for this gender difference are not clear but are consistent with a recent report by Owens et al., who also observed that lower morning cortisol levels increase the odds ratio for increased risk of depression in boys but not girls [37]. One suggested explanation for this anomaly is that adolescent boys may be less able to compensate for the neurobiological effects of chronically raised cortisol than girls. However this hypothesis remains to be verified.

When psychosocial stress as the dominant factor in predicting depression was removed from the model, variables such as hours of sleep, and waist hip ratio became significant. It is widely accepted that poor sleep is predictive of depression in adults [38]. A recent 
meta-analysis by Lovato and Gradisar concluded that sleep disturbance is also a precursor to the development of depression in adolescents [39]. These authors suggest that the identified delay in timing of the circadian rhythm associated with sleep in adolescence may increase the risk of depression [39]. This association between sleep and psychological health was also reflected in the current study. After accounting for stress, sleep duration emerged as an effective discriminator for the risk of depression in both boys and girls. Boys reporting $>8.5 \mathrm{hrs}$ sleep reported no depressive symptoms (Figure 5 ). This is consistent with the general observation that $>8 \mathrm{hrs}$ sleep duration per night meets the needs of adolescents [40]. For the girls, extreme depression was only represented in those reporting $<5.5 \mathrm{hrs}$ sleep per night, further strengthening the link between depression and sleep duration. However, not all girls getting $<5.5$ hrs sleep/night reported depressive symptoms indicating that a wider array of variables than those available in this study is required to further differentiate this group.

In girls receiving $>5.5 \mathrm{hrs}$ sleep, being overweight (i.e. waist to hip ratio of $>0.83$ ) increased the risk for mild depression. Previous studies have shown that weight gain during adolescence is significantly linked to a higher incidence of depression in young females [41, 42]. Being overweight has been associated with a number of negative biological and psychosocial sequelae that link to depression including, cortisol hyper reactivity, increased oxidative and inflammatory activity, nutritional deficiency and negative socialisation [34, 43-45].

\section{CONCLUSION}

A number of studies have reported associations between the incidence of depression and individual variables such as stress, omega-3 PUFA, cortisol, weight and sleep. In this study we attempted to outline the predictive value of each of these variables relative to each other in correctly identifying depression in a cohort of adolescents.

Overall these results indicate that psychosocial stress is the most significant predictor of depression in this adolescent cohort, however omega-3 PUFA levels, HPA axis activation, hours of sleep and body size (i.e. $\mathrm{BMI}$ and waist to hip ratio) also make significant contributions.

At a practical level these results indicate that when developing strategies to combat the prevalence of depression in adolescents the most successful outcomes will be obtained by focussing on the child's psychosocial distress as this was the most significant driver of the depressive phenotype. However our results also indicate that improving neurobiological function by ensuring adequate omega-3 PUFA levels and sufficient sleep duration could also significantly assist in moderating the development and progression of depression. Body size (i.e. waist to hip ratio) was useful in identifying depression in adolescent girls, but was relatively weak, being effective only in those girls with poorer sleep patterns.

Therefore the results from this study can provide a rational basis for prioritizing strategies to effectively treat or prevent depression in the adolescent population.

\section{LIMITATIONS}

The general applicability of these findings may be affected by two factors present in this cohort. 1) Adolescents taking part in this study are from a generally privileged demographic within Australia with the largest percentage of students from homes in the high socioeconomic band [46]. Thus the average omega-3 index is likely higher than for those children from less privileged homes [12]. As this demographic also, generally has both the education and financial resources to provide a best-case-healthy environment for their children the number of adolescents reporting symptoms of depression and anxiety in this study may be an underestimate of the problem among adolescents in the wider population. 2) This study cohort also had a higher percentage of girls than boys. Thus the observed gender biases need to be verified using a larger cohort.

\section{ACKNOWLEDGEMENTS}

The authors wish to thank the students, teachers, parents and ancillary personnel who assisted in this study and the NOVUS Foundation for their generous research grant to $R G$ and MJM to fund this project.

\section{REFERENCES}

[1] Fombonne E. Depressive disorders: time trends and possible explanatory mechanisms. In: Rutter $M$, Smith $D$, editors. Psychosocial disorders in young people: time trends and their causes. Chichester: Wiley 1995; pp. 544-615.

[2] Kessler RC, Berglund P, Demler O, Jin R, Merikangas KR, Walters EE. Lifetime prevalence and age-of-onset distributions of DSM-IV disorders in the national comorbidity survey replication. Arch Gen Psychiatry 2005; 62: 593-602. http://dx.doi.org/10.1001/archpsyc.62.6.593 
[3] Moon L, Meyer P, Grau J. Australia's young people 1999: their health and wellbeing. AIHW [PHE 19]. 2000; [cited 2014 October 23]; Available from: http://www.aihw.gov.au/ publication-detail/?id=6442467120

[4] Balazs J, Miklosi M, Kereszteny A, et al. Adolescent subthreshold-depression and anxiety: psychopathology, functional impairment and increased suicide risk. J Child Psychol Psychiatry 2013; 54: 670-7. http://dx.doi.org/10.1111/jcpp.12016

[5] Kessler RC, Amminger GP, Aguilar-Gaxiola S, Alonso J, Lee $S$, Üstün TB. Age of onset of mental disorders: a review of recent literature. Curr Opin Psychiatry 2007; 20: 359-64. http://dx.doi.org/10.1097/YCO.0b013e32816ebc8c

[6] Cabello M, Mellor-Marsá B, Sabariego C, Cieza A, Bickenbach J, Ayuso-Mateos J. Psychosocial features of depression: a systematic literature review. J Affect Disord 2012; 141: 22-33. http://dx.doi.org/10.1016/j.jad.2011.12.009

[7] Nguyen-Rodriguez S, Chou C, Unger J, Spruijt-Metz D. BMI as a moderator of perceived stress and emotional eating in adolescents. Eat Behav 2008; 9: 238-46.

http://dx.doi.org/10.1016/j.eatbeh.2007.09.001

[8] Flint F, Kendler KS. The genetics of major depression. Neuron 2014; 81: 484-503.

http://dx.doi.org/10.1016/j.neuron.2014.01.027

[9] National Center for Health Statistics, National Center for Chronic Disease Prevention and Health Promotion. (2000). CDC growth charts. 2000; [cited 2014 October 23]; Available from: http://www.cdc.gov/growthcharts

[10] Lovibond PF, Lovibond SH. The structure of negative emotional states: comparison of the Depression Anxiety Stress Scales (DASS) with the Beck Depression and Anxiety Inventories. Behav Res Ther 1995; 33: 335-43.

http://dx.doi.org/10.1016/0005-7967(94)00075-U

[11] Lepage G, Roy GC. Direct transesterification of all classes of lipid in a one-step reaction. J Lipid Res 1986; 27: 114-20. http://www.jlr.org/search?author1=lepage+G\&fulltext=\&pubd ate_year $=1986 \&$ volume $=27 \&$ firstpage $=114 \&$ submit $=y e s$

[12] Grant R, Guest J, Bilgin A, Morris M, Garg M, Pearce R. Suboptimal omega 3 levels in Australian adolescents. Int $J$ Child Health Nutrit 2013; 2: 309-15. http://www.lifescienceglobal.com/journals/international-journal-of-child-health-andnutrition/volume-2-number-4/93-abstract/ijchn/382-abstractsuboptimal-omega-3-levels-in-australian-adolescents

[13] Harris WS. Omega-3 fatty acids and cardiovascular disease: a case for omega- 3 index as a new risk factor. Pharmacol Res 2007; 55: 217-23. http://dx.doi.org/10.1016/j.phrs.2007.01.013

[14] Harris WS. The omega-3 index: from biomarker to risk marker to risk factor. Curr Atheroscler Rep 2009; 11: 411-7. http://dx.doi.org/10.1007/s11883-009-0062-2

[15] Bell J, Mackinlay E, Dick J, Younger I, Lands B, Gilhooly T. Using a fingertip whole blood sample for rapid fatty acid measurement: method validation and correlation with erythrocyte polar lipid compositions in UK subjects. Br J Nutr 2011; 106: 1408-15.

http://dx.doi.org/10.1017/S0007114511001978

[16] Hastie T, Tibshirani R, Friedman J. The elements of statistical learning: data mining, inference, and prediction. $2^{\text {nd }}$ ed. New York: Springer-Verlag 2009. http://dx.doi.org/10.1007/978-0-387-84858-7

[17] Han J, Kamber M. Data mining: Concepts and techniques. $2^{\text {nd }}$ ed. San Francisco: Morgan Kaufmann Publishers 2006.

[18] Kendler K, Karkowski LM, Prescott C. Causal relationship between stressful life events and the onset of major depression. Am J Psychiatry 1999; 156: 837-41.

http://dx.doi.org/10.1176/ajp.156.6.837
[19] Swaab DF, Bao A, Lucassen PJ. The stress system in the human brain in depression and neurodegeneration. Ageing Res Rev 2005; 4: 141-94 http://dx.doi.org/10.1016/j.arr.2005.03.003

[20] Martins JG. EPA but not DHA appears to be responsible for the efficacy of omega-3 long chain polyunsaturated fatty acid supplementation in depression: evidence from a metaanalysis of randomized controlled trials. J Am Coll of Nutrit 2009; 28: 525-42.

http://dx.doi.org/10.1080/07315724.2009.10719785

[21] Staner L. Comorbidity of insomnia and depression. Sleep Med Rev 2010; 14: 35-46. http://dx.doi.org/10.1016/j.smrv.2009.09.003

[22] Bazargan-Hejazi S, Alvarez G, Teklehaimanot S, Nikakhtar $\mathrm{N}$, Bazargan M. Prevalence of depression symptoms among adolescents aged 12-17 years in California and the role of overweight as a risk factor. Ethn Dis 2010; 20; S1-107-15. http://www.ncbi.nlm.nih.gov/pubmed/20521397

[23] Hazell P. Depression in children and Adolescents. Am Fam Physician 2012; 86: 1138-9. http://www.aafp.org/afp/ 2012/1215/p1138.html

[24] Bhatia SK, Bhatia SC. Childhood and adolescent depression. Am Fam Physician 2007; 75: 73-80. http://www.aafp.org/ link_out?pmid=17225707

[25] O'Sullivan C. The psychosocial determinants of depression: a lifespan perspective journal of nervous and mental disease: $\mathrm{J}$ Nerv Ment Dis 2004; 192: 585-94.

http://dx.doi.org/10.1097/01.nmd.0000138225.19549.dd

[26] Hoffmann F, Petermann F, Glaeske G, Bachmann, CJ. Prevalence and comorbidities of adolescent depression in Germany: an analysis of health insurance data. Z Kinder Jugendpsychiatr Psychother 2012; 40: 399-404. http://dx.doi.org/10.1024/1422-4917/a000199

[27] Meyer BJ , Grenyer BFS, Crowe T, Howe PRC. Improvement of major depression is associated with increased erythrocyte DHA. Lipids 2013; 48: 863-8.

http://dx.doi.org/10.1007/s11745-013-3801-7

[28] Freeman M, Rapaport M. Omega-3 fatty acids and depression: From cellular mechanisms to clinical care. J Clin Psychiatry 2011; 72: 258-9. http://dx.doi.org/10.4088/JCP.11ac06830

[29] Mamalakis G, Kiriakakis M, Tsibinos G, et al. Depression and serum adiponectin and adipose omega- 3 and omega- 6 fatty acids in adolescents. Pharmacol Biochem Behav 2006; 85: 474-9.

http://dx.doi.org/10.1016/j.pbb.2006.10.008

[30] Swenne I, Rosling A, Tengblad S, Vessby B. Omega-3 polyunsaturated essential fatty acids are associated with depression in adolescents with eating disorders and weight loss. Acta Paediatrica 2011; 100: 1610-15. http://www.nedc.com.au/researchlink/485/omega-3polyunsaturated-essential-fatty-acids-are-

[31] Giedd J, Blumenthal J, Jeffries N, et al. Brain development during childhood and adolescence: a longitudinal MRI study. Nat Neurosci 1999; 2: 861-3.

http://dx.doi.org/10.1038/13158

[32] Carver J, Benford V, Han B, Cantor AB. The relationship between age and the fatty acid composition of cerebral cortex and erythrocytes in human subjects. Brain Res Bull 2001; 56: 79-85. http://dx.doi.org/10.1016/S0361-9230(01)00551-2

[33] McNamara RK, Jandacek R, Tso $P$, et al. Low docosahexaenoic acid status is associated with reduced indices in cortical integrity in the anterior cingulate of healthy male children: A 1H MRS study. Nutr Neurosci 2013; 16: 183-90.

http://dx.doi.org/10.1179/1476830512Y.0000000045

[34] Fu C, Steiner H, Costafreda S. Predictive neural biomarkers of clinical response in depression: A meta-analysis of 
functional and structural neuroimaging studies of pharmacological and psychological therapies. Neurobiol Dis 2013; 52: 75-83 http://dx.doi.org/10.1016/j.nbd.2012.05.008

[35] Bao A. M, Meynen G, Swaab D. F. The stress system in depression and neurodegenereation: Focus on human hypothalamus. Brain Res Rev 2008; 57: 531-53. http://dx.doi.org/10.1016/j.brainresrev.2007.04.005

[36] Dockray S, Susman E, Dorn LD. Depression, cortisol reactivity and obesity in childhood and adolescence. $\mathrm{J}$ Adolesc Health 2009; 45: 344-50. http://dx.doi.org/10.1016/j.jadohealth.2009.06.014

[37] Owens M, Herbert J, Jones PB, et al. Elevated morning cortisol is a stratified population-level biomarker for major depression in boys only with high depressive symptoms. Proc Natl Acad Sci USA 2014; 111: 3638-43. http://dx.doi.org/10.1073/pnas.1318786111

[38] Alvaro P, Roberts R, Harris J. A systematic review assessing bidirectionality between sleep disturbances, anxiety and depression. Sleep 2013; 367: 1059-68. http://www.journalsleep.org/ViewAbstract.aspx?pid=29009

[39] Lovato N, Gradisar M. A meta-analysis and model of the relationship between sleep and depression in adolescents: Recommendations for future research and clinical practice. Sleep Med Rev 2014; in press. http://dx.doi.org/10.1016/j.smrv.2014.03.006

[40] Carskadon M. Sleep in adolescents: The perfect storm. Pediatr Clin North Am 2011; 58: 637-47. http://dx.doi.org/10.1016/.j.pcl.2011.03.003
[41] Frisco ML, Houle JN, Lippert AM. Weight change and depression among US young women during the transition to adulthood. Am J Epidemiol 2013; 178: 22-30. http://dx.doi.org/10.1093/aje/kws462

[42] Richardson LP, Davis R, Poulton R, McCauley E, Moffitt TE, Caspi A, et al. A longitudinal evaluation of adolescent depression and adult obesity. Arch Pediatr Adolesc Med 2003; 157: 739-45. http://dx.doi.org/10.1001/archpedi.157.8.739

[43] Faienza M, Francavilla R, Goffredo R, et al. Oxidative stress in obesity and metabolic syndrome in children and adolescents. Horm Res Paediatr 2012; 78: 158-64. http://dx.doi.org/10.1159/000342642

[44] Markovic TP, Natoli SJ. Paradoxical nutritional deficiency in overweight and obesity: the importance of nutrient density. MJA 2009; 190: 149-51. https://www-mja-comau.wwwproxy0.library.unsw.edu.au/journal/2009/190/3/parad oxical-nutritional-deficiency-overweight-and-obesityimportance-nutrient

[45] Madowitz J, Knatz S, Maginot T, Crow SJ, Boutelle KN. Teasing, depression and unhealthy weight control behaviour in obese children. Pediatr Obes 2012; 7: 446-52. http://www.ncbi.nlm.nih.gov/pubmed/22991215\#

[46] Australian Bureau of Statistics. Socio-economic indexes for areas (SEIFA) - technical paper. [2039.0.55.001]. 2006;[cited 2014 October 21]; Available from: http://www.abs.gov.au/ ausstats/abs@.nsf/mf/2039.0.55.001/

(C) 2015 Grant et al.; Licensee Lifescience Global.

This is an open access article licensed under the terms of the Creative Commons Attribution Non-Commercial License (http://creativecommons.org/licenses/by-nc/3.0/) which permits unrestricted, non-commercial use, distribution and reproduction in any medium, provided the work is properly cited. 